\title{
Car Front Towing Hook Analysis and Structural Improvements Based on CAE
}

\author{
Zhiping Wang
}

Dept. of Automotive Eng., Anhui Technical College of Mechanical and Electrical Engineering, Wuhu Anhui 241002, China

aemail:ahjdwzp@126.com

Keywords: Front towing hook, structural strength, Structural Improvements

\begin{abstract}
In order to improve the development quality of car towing hook, through a car front towing hook design and development, we analyze the strength of towing hook and local parts using CAE. By comparison with the results and the target value, we evaluate its structural strength and determine the improvement program. The improvement program shows that both the strength and residual deformation meet the requirements.
\end{abstract}

\section{Introduction}

The front towing hook of car is a kind of graft gear which helps vehicles trapped in danger get out of the Harm's Way by drawing support from external force. As safety guarantee device of vehicles, if there is flaw existed in the design of towing hook, it will not only bring damage to parts of vehicle but also direct or indirect harm to person. So FEA analysis of situation like stress, deformation of towing hook of car is significant ${ }^{[1-3]}$.

The basis of CAE technology is finite element method. Its basic idea is to solve numerical value physical problems through variation principle. That is to disperse digital analogy into several little units, substitute original structure with discrete structure, use discrete structure as approximation mechanical model of real structure. The numerical calculation is conducted in this discrete structure $^{[4]}$.

\section{Building up of towing hook FEM}

\subsection{Units type and mesh generation}

This thesis is taking a certain car as an example. Towing hook is solid round steel which screw jointed with towing hook pipe. Screw pipe is welded onto front inner and outer reinforced plate by using $\mathrm{CO}_{2}$. In order to save the calculation cost, the author intercepts some areas of towing hook and local parts and then carries out mesh generation of interception. According to 3D-Mode in CATIA, the author builds FEM model. In the process of building FEM model, attention should be paid to ${ }^{[5-6]}$ :

(1) Towing hook and towing hook pipe are solid model. The author uses PSHELL shell unit model building for stamping parts around towing hook. What's more, necessary contact pairs being built among different stamping parts.

(2) Carry out *Tie touch in the screw joint of towing hook and towing hook pipe. Use stiffness unit simulation in wield joint of towing hook pipe and front inner and outer plate and reinforced plate. Apply cweld unit simulation on tack wielding of local stamping parts.

\subsection{Material properties}

Towing hook and local parts connection is as Fig.1, towing hook material is $\mathrm{Q} 235-\mathrm{A}\left(\sigma_{b}=422.3 \mathrm{MPa}\right)$, towing hook pipe material is $40 \operatorname{Cr}\left(\sigma_{b}=902 \mathrm{MPa}\right)$, front protective material is $\mathrm{B} 340 / 590 \mathrm{DP}\left(\sigma_{b}=788.2 \mathrm{MPa}\right)$, reinforcing plate material is B340/590DP, anti-collision lower plate material is Q235-B $\sigma_{b}=540 \mathrm{MPa}$, anti-collision upper plate material is $\operatorname{DP} 1000\left(\sigma_{b}=1159.6 M P a\right)$. 


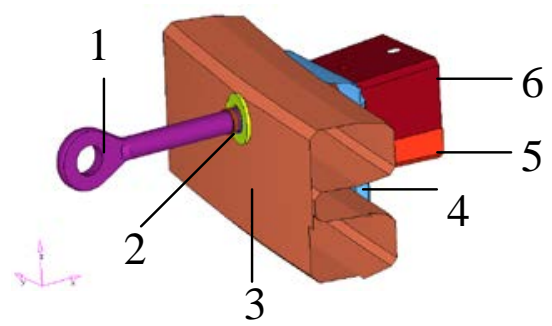

1-towinging hook 2-towing hook pipe 3-pront protection plate 4-reinfrcing plate

5-anti-collison lower plate 6-anti-collison upper plate

Fig. 1 Towing hook and local parts structure

\subsection{Determination of boundary conditions and load working condition}

For constraint load, we choose front protective plate section and anti-collision box section. For load processing, application of force is in towing hook. But for easy check and calibration, we choose $\mathrm{z}$ typical working conditions. Working condition 1: applied force is: (finished car mass +5 person weight + five persons' luggage)/2, its direction is along the $X$ axis negative. See Fig.2; working condition 2: applied force is (finished car mass +5 person weight+five persons' luggage) /2, its direction is on the XY plane, forming 30 angular degree with negative $\mathrm{X}$ axis ${ }^{[2]}$. See Fig.3.

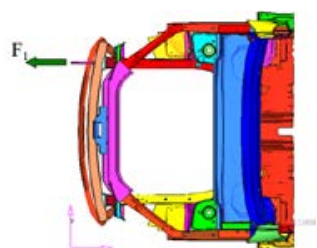

Fig.2 Straight pull load

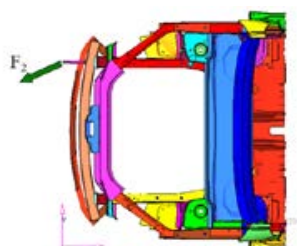

Fig.3 Inclined pull load

\subsection{Strengthen analysis of towing hook}

Fig. 4 is the stress cloud calculated under working condition 1 .We can see that the maximum stress of towing hook and towing hook pipe is less than yield limit of local parts. The maximum stress of towing hook pipe is in the joint place of stowing hook and screw of which the maximum stress is $527 \mathrm{MPa}$. The maximum stress of front protective plate is in wielding palace of it to towing hook pipe of which the maximum stress 191MPa. The maximum stress of reinforcing plate is in wielding place of it to towing hook pipe of which the maximum $648 \mathrm{MPa}$ is less than material ultimate limit. The maximum stress area of anti-collision box upper and lower plate is stiffness constraint place, not belong to danger area.
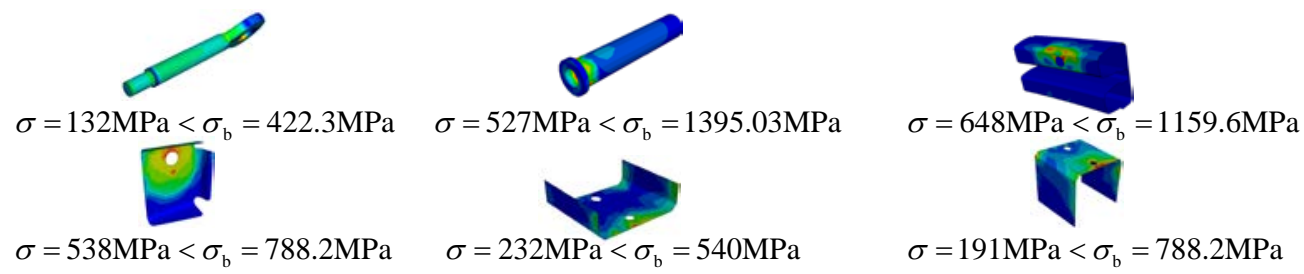

Fig.4 Towing hook and local parts stress cloud (working condition 1)

Fig. 5 is the stress cloud of towing hook and local parts under working condition 2. We can see that the maximum stress of towing hook and towing hook pipe is $447 \mathrm{MPa}$ which is beyond ultimate limit 422.3MPa of towing hook materialQ235-A. Thus there exists safety loophole. The maximum stress of stowing hook pipe and reinforcing plate is 1096MPa which is beyond ultimate limit 902MPa of material 40Cr, thus existing safety loophole. Stress concentration occurs in wielding place of front protective plate and reinforcing plate to stowing hook which is less than material ultimate limit, thus no safety loophole. The maximum stress area of anti-collision box upper and lower plate is less than material ultimate limit and also in the constraint stiffness joint place, thus existing no safety loophole. 

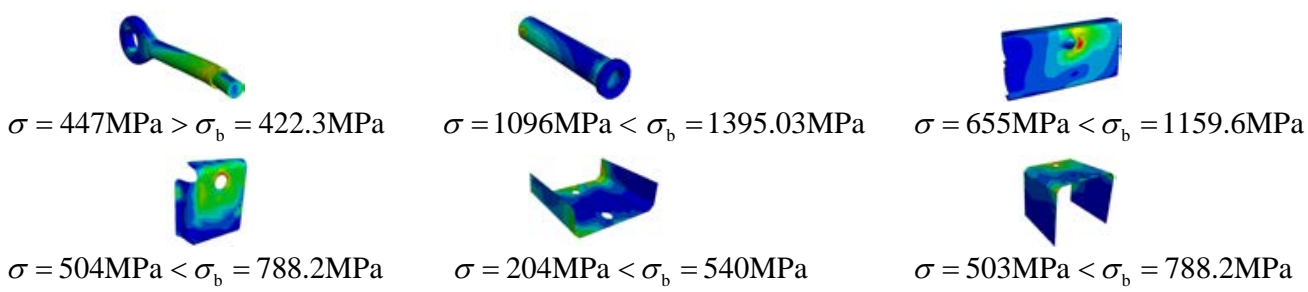

Fig.5 Towing hook and local parts (working condition 2 )

Fig.6 is the plastic deformation curve of towing hook and local parts. We can see that once the working condition 1 is unloaded, the residual deformation is $2.4 \mathrm{~mm}$ which is less than the standard value. While once the working condition 2 is off loaded, the residual deformation is $25 \mathrm{~mm}$, far beyond the target value.

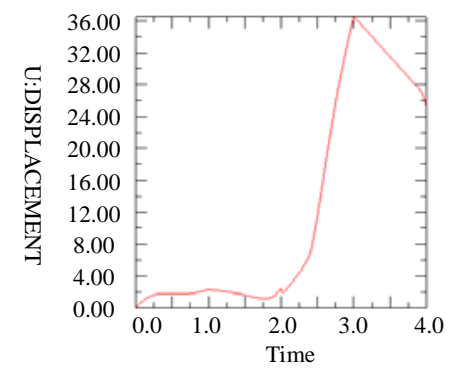

Fig.6 Plastic deformation curve of towing hook and local parts

The two typical working conditions show that resistance to lateral bending of towing hook is not strong, especially when it is under working condition 2 of which maximum stress of towing hook and towing hook pipe is beyond the strengthen limit of material. So we can judge that strengthen of towing hook is not up to the design requirement. Plastic deformation curve shows that when under working condition 1 , deformation requirement is satisfied, however when under working condition 2 , the requirement is far from satiated.

\section{Improvement program and analysis}

According to the above analysis of the strength and deformation, we need to make some improvements for towing hook and mounting position. The main adjustment is for the towing hook strength and pipe installation location. Fetch the towing hook pipe from the absorbing energy box and install it in the front beam. Weld the front end to the beam. The diameter of the towing hook increases from $18 \mathrm{~mm}$ to $24 \mathrm{~mm}$, see Fig.7.

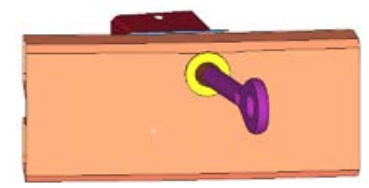

(a) original program

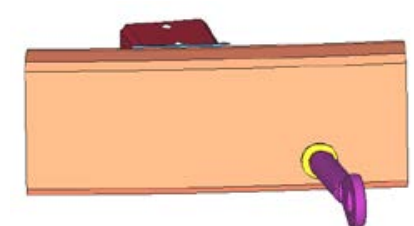

(b) improving program

Fig.7 Schematic diagram of towing hook improvement program

Tab. 1 show the maximum stress of the improvement program in working condition 1 and 2 . We can see that the maximum stress of all components of the improved program is less than material ultimate limit for different materials.

Tab.1 The maximum stress of all components for the improved program

\begin{tabular}{|c|c|c|c|c|c|c|}
\hline component & 1 & 2 & 3 & 4 & 5 & 6 \\
\hline $\begin{array}{c}\text { working condition } \\
1\end{array}$ & 131MPa & $415 \mathrm{MPa}$ & $\begin{array}{l}1151 \\
\text { MPa }\end{array}$ & $705 \mathrm{MPa}$ & $456 \mathrm{MPa}$ & $154 \mathrm{MPa}$ \\
\hline $\begin{array}{c}\text { working condition } \\
2\end{array}$ & $406 \mathrm{MPa}$ & $955 \mathrm{MPa}$ & $926 \mathrm{MPa}$ & $634 \mathrm{MPa}$ & $509 \mathrm{MPa}$ & $926 \mathrm{MPa}$ \\
\hline
\end{tabular}


Fig.8 is the plastic deformation of the improvement program in the two typical working conditions. The residual deformation of working condition 1 is $0.55 \mathrm{~mm}$, lower than the target value. The residual deformation of working condition 2 is $3.11 \mathrm{~mm}$, satisfying the target value.

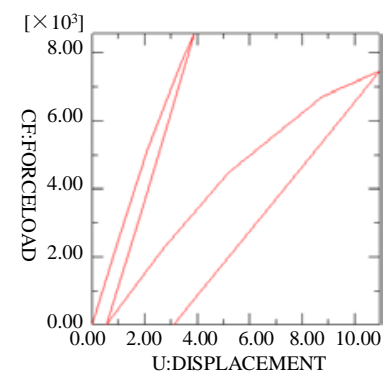

Fig.8 The plastic deformation curve of improvement program

Through the verification of the improvement program, we can see that the lateral deformation after thickening of the towing hook obviously decreased and meets the target value. The computational model considers that when the towing hook twists in the end, the end face of the crew thread and the end face of casing will fit, so the end face of the casing will restrict the towing hook plastic deformation someh

If the towing hook twists not entirely, the towing hook plastic deformation will increase. The plastic deformation is mainly caused by the deformation of twisting end and the outer end of the connecting portion. So we can decrease the diameter of outer end and increase the diameter of twisting end properly.

\section{Conclusion}

In this paper, through the FEM simulation analysis of a car towing hook, we find the inadequate of the towing hook design, and provide the improvement program according to the analysis results. The improvement program shows that both the strength and residual deformation meet the requirements. The result shows that CAE technology is useful for towing hook structure design and improvements.

\section{References}

[1] Wei Fu,Ying Zhang. Towing hook strength analysis for passenger car,Journal of Hefei University,Vol.32 No.Sup.Nov.2009

[2] Chengen He,Dalu Duan.Strength Analysis of Draw Hook Pin of Certain Automobile on Several Conditions,NO.10,2010(Cumulatively NO.280):38-42

[3] Haiping Yang,Liangmo Wang,Shuxi Peng,Jiazhu Su,Liukai Yuan.Analysis of the Off-road Vehicle's Frame Based on CAE.Mechanical Science and Technology for Aerospace Engineering.June 2011.Vol.30.No.6:1001-1006

[4] Yumei Hu.Basic Theory of Structural Strength of Vehicle and CAE Analysis Technology [M]. Chongqing:Chongqing University Press,2009

[5] Yiping Shi.Yurong Zhou.Detailed Examples of Finite Element Analysis for ABAQUS.Chine Mechine Press.2006:166-171

[6] Altair HyperMorks 7.0 User's Guide[G].Altair Engineering Inc,2000 